\title{
Guided Internet-Based Cognitive Behavioral Therapy for Insomnia: Health-Economic Evaluation From the Societal and Public Health Care Perspective Alongside a Randomized Controlled Trial
}

Claudia Buntrock ${ }^{1}, \mathrm{PhD}$; Dirk Lehr ${ }^{2}, \mathrm{PhD}$; Filip Smit ${ }^{3,4,5}, \mathrm{PhD}$; Hanne Horvath ${ }^{6}, \mathrm{PhD}$; Matthias Berking ${ }^{1}, \mathrm{PhD}$; Kai Spiegelhalder ${ }^{7}$, PhD; Heleen Riper ${ }^{5,8}, \mathrm{PhD}$; David Daniel Ebert ${ }^{9}, \mathrm{PhD}$

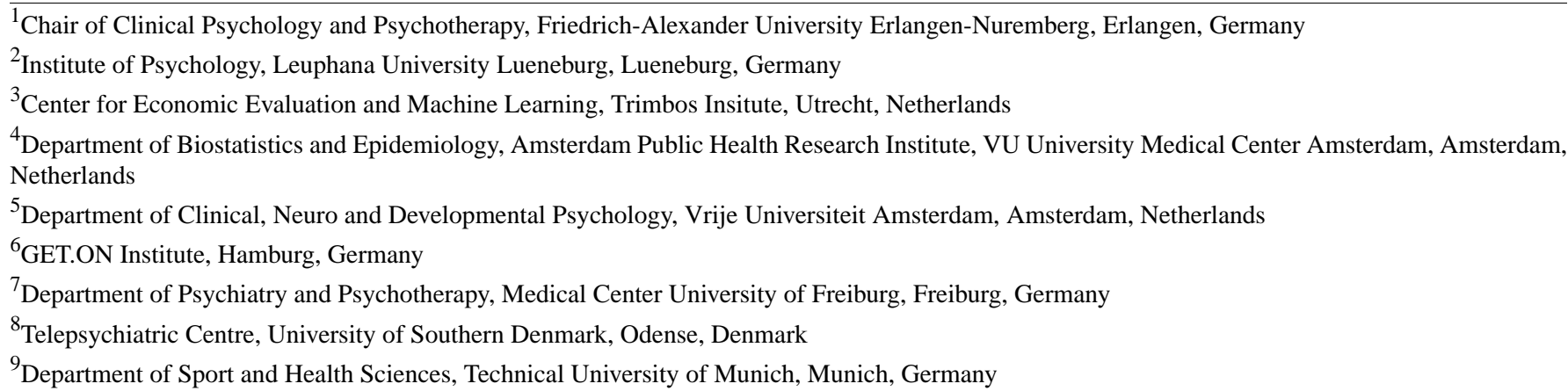

\section{Corresponding Author:}

Claudia Buntrock, $\mathrm{PhD}$

Chair of Clinical Psychology and Psychotherapy

Friedrich-Alexander University Erlangen-Nuremberg

Nägelsbachstr 25a

Erlangen, 91052

Germany

Phone: 49091318567568

Email: claudia.buntrock@fau.de

\section{Abstract}

Background: The evidence base for internet-based cognitive behavioral therapy for insomnia (iCBT-I) is firm; however, little is known about iCBT-I's health-economic effects.

Objective: This study aimed to evaluate the cost-effectiveness and cost-utility of iCBT-I in reducing insomnia among schoolteachers.

Methods: Schoolteachers ( $\mathrm{N}=128)$ with clinically significant insomnia symptoms and work-related rumination were randomized to guided iCBT-I or a wait list control group, both with unrestricted access to treatment as usual. Health care use, patient and family expenditures, and productivity losses were self-assessed and used for costing from a societal and a public health care perspective. Costs were related to symptom-free status (score $<8$ on the insomnia severity index) and quality-adjusted life years (QALYs) gained. Sampling error was handled using nonparametric bootstrapping.

Results: Statistically significant differences favoring the intervention group were found for both health outcomes (symptom-free status yes or no: $\beta=.30 ; 95 \%$ CI 0.16-0.43; QALYs: $\beta=.019,95 \%$ CI 0.01-0.03). From a societal perspective, iCBT-I had a $94 \%$ probability of dominating the wait list control for both health outcomes. From a public health care perspective, iCBT-I was more effective but also more expensive than the wait list control, resulting in an incremental cost-effectiveness ratio of $€ 650$ per symptom-free individual. In terms of QALYs, the incremental cost-effectiveness ratio was $€ 11,285$. At a willingness-to-pay threshold of $€ 20,000$ per QALY gained, the intervention's probability of being cost-effective was $89 \%$.

Conclusions: Our trial indicates that iCBT could be considered as a good value-for-money intervention for insomnia.

Trial Registration: German Clinical Trial Registry: DRKS00004700; https://tinyurl.com/2nnk57jm

International Registered Report Identifier (IRRID): RR2-10.1186/1745-6215-14-169

(J Med Internet Res 2021;23(5):e25609) doi: 10.2196/25609 


\section{KEYWORDS}

insomnia; internet-based cognitive behavioural therapy; iCBT-I; economic evaluation; cost-effectiveness; cost-utility; cognitive behavioral therapy; behavior; sleep; economics; public health; perspective

\section{Introduction}

Insomnia is characterized by difficulties in initiating or maintaining sleep and/or early morning awakenings that occur 3 nights or more per week, for at least 3 months, resulting in poor sleep quality and significant daytime impairment [1]. Insomnia is one of the most common sleep disorders among adults. Prevalence estimates range from $6 \%$ for insomnia disorder [2] to $25 \%$ for insomnia symptoms [3].

Insomnia is associated with a range of adverse health consequences for individuals, including poor daytime functioning [4] and reduced health-related quality of life [5]. In view of its high prevalence and its debilitating nature, insomnia is related to a substantial health and economic burden. As such, it increases the risk of future mental disorders (eg, major depressive disorder) [6]. Economic costs stem from both absenteeism and reduced productivity while at work (ie, presenteeism) [7] as well as increased health care utilization, (eg, medication prescription [8,9]).

In order to reduce the personal and economic burden of insomnia, it is essential to implement interventions that can improve sleep. American and European guidelines recommend cognitive behavioral therapy (CBT) as first-line treatment for insomnia disorder $[10,11]$ due to its substantial clinical evidence base [12]. However, despite this recommendation, CBT for insomnia (CBT-I) is not widely available, mainly due to a shortage of therapists and available resources [13]. In addition, only $37 \%$ of those suffering from insomnia seek professional help [3].

Internet-based CBT intervention for insomnia (iCBT-I) has been touted as a solution that can bridge this gap in health care [14]. Meta-analytic evidence demonstrated that iCBT-I is effective in treating insomnia with large effect sizes at posttreatment (eg, Cohen's d $=1.09 ; 95 \%$ CI 0.74-1.45) for insomnia severity [15]. Effect sizes are comparable to those found in individual face-to-face delivered CBT-I (eg, $\mathrm{d}=1.11$; 95\% CI 0.94-1.28) [12].

Although the effectiveness of (i)CBT-I has been demonstrated, research on its economic costs and benefits is still limited [16]. Previous reviews have argued that treating insomnia costs less compared to doing nothing $[17,18]$. A recent review on CBT-I interventions $(\mathrm{N}=7)$ using a dominance ranking framework showed that CBT-I was cost-effective compared to pharmacotherapy or no treatment [19]. However, only 2 studies have evaluated the economic effects of an iCBT-I intervention, but they suggested that iCBT-I provides superior health improvements at reduced costs [20,21]. To the best of our knowledge, no study has yet investigated the economic merits of iCBT-I from a societal perspective (including reductions in direct medical costs, patient and family costs, and indirect costs stemming from productivity losses) and from the public health care perspective (including only direct medical costs).
The aim of the this paper was thus to assess, from a societal and public health care perspective, the cost-effectiveness and cost-utility of a guided iCBT-I intervention to reduce insomnia symptoms in currently employed schoolteachers. The health economic evaluation presented here was conducted alongside a randomized controlled trial [22]. A previous publication reported the clinical effects of the iCBT-I intervention (6-month follow-up: Cohen $\mathrm{d}=1.43$; 95\% CI 1.04-1.82) [23].

\section{Methods}

\section{Study Design}

We conducted and reported the health-economic evaluation in agreement with the Consolidated Health Economic Evaluation Reporting Standards (CHEERS) statement [24] and the guidelines from the International Society for Pharmacoeconomics and Outcomes Research (ISPOR) [25]. The economic evaluation was performed from a societal perspective (ie, all relevant costs) and a public health care perspective (ie, direct medical costs) alongside a pragmatic 2-armed randomized controlled trial to establish the cost-effectiveness and cost-utility of a guided iCBT-I intervention as an adjunct to treatment as usual (TAU) for schoolteachers with insomnia compared to a wait list control condition with unrestricted access to TAU. Self-report questionnaires to assess costs and effects were collected at baseline, posttreatment (only health effects; 8 weeks after randomization), and 6-month follow-up via a secured online-based assessment system (Advanced Encryption Standard, 256-bit encrypted). Full details of the trial design can be found elsewhere [22]. The study was approved by the ethics committee of the University of Marburg (reference number: 2013-01K) and is registered under DRKS00004700 in the German clinical trial registry.

\section{Procedure}

Participants were recruited in Germany from March 2013 to September 2013 using email distribution lists to primary, secondary, and vocational schools, which were provided by the Ministry of Education in the German state of Nordrhein-Westfalen. Currently employed schoolteachers aged 18 and above with clinically significant insomnia symptoms (Insomnia Severity Index [ISI] >14) and elevated work-related rumination (Irritation scale, subscale "Cognitive Irritation" >14) were included in the study [22]. The exclusion criterion was current psychotherapy for insomnia and/or suicidal ideation (Beck Depression Inventory item on suicidality $>1$ ). People taking sleep medication were not excluded from the study but were required to keep their medication on a stable dose during the study period. The Consolidated Standards of Reporting Trials (CONSORT) study flowchart and participants' characteristics at baseline can be found elsewhere [23]. In brief, 128 schoolteachers were recruited into the trial with 64 randomized to the intervention and 64 to the wait list control condition. The average participant was female $(95 / 128,74 \%)$, 
48 years of age (SD 10), married or in a partnership (92/128, $72 \%$ ), and had a diagnosis of a primary insomnia (100/128, $78.1 \%$ ) with moderate severity, and $14 \%$ (18/128) had a comorbid major depression [23]. Randomization took place at the individual level in a ratio of 1:1 and was conducted centrally by an independent research staff member not otherwise involved in the study using an automated web-based program (randomisation.eu). Study participants were not masked to their treatment allocation due to the nature of the psychological intervention.

\section{Interventions}

In this pragmatic trial, all study participants had unrestricted access to TAU. In Germany, TAU for elevated insomnia symptoms usually includes visits to the general practitioner followed by more intensive interventions, such as cognitive behavioral therapy and medication if insomnia symptoms persist or worsen.

\section{iCBT-I Intervention (GET.ON Recovery)}

The iCBT-I intervention (GET.ON Recovery [22,23]) has been specifically tailored to schoolteachers experiencing work-related stress and insomnia. The intervention was mainly based on cognitive behavioral methods (eg, sleep restriction therapy, stimulus control therapy, relaxation, sleep hygiene, and cognitive interventions) [26]. These methods were supplemented by techniques effective in reducing work stress and fostering mental detachment from work-related problems derived from behavioral activation [27], metacognitive therapy [28], gratitude research [29], and research on boundary management [30]. The intervention consisted of 6 weekly modules. Overall, of the 64 participants, 61 (95.3\%) completed all 6 modules [23]. Participants received written feedback on each completed module by an eCoach (ie, a trained clinical psychologist), who followed a standardized coaching manual. To maximize the comparability of the participants and maintain the guidance at a minimal level, eCoaches were advised that the time spent on each participant per module should not exceed 30 minutes; thus, the total amount of time spent on each participant was approximately 3 hours for the total duration of the intervention [23]. eCoaches were supervised by a clinical psychologist.

\section{Wait List Control Condition}

In addition to TAU, individuals in the control group were eventually granted access to the unguided version of the intervention after completing the final assessment at 6 months post baseline.

\section{Outcomes}

\section{ISI Symptom-Free Status}

The health outcome in the cost-effectiveness analysis was symptom-free status defined as a score $<8$ on the ISI [31]. The ISI is a 7-item instrument answered on a 5-point Likert scale with a total score ranging from 0 to 28 . The psychometric properties of the online version of the questionnaire have been well established [32]. In the current study, internal consistency was set at Cronbach $\alpha=.91$.

\section{Quality-Adjusted Life Years}

Quality-adjusted life years (QALYs) were used as a health outcome in the cost-utility analysis (CUA). QALYs were based on the 6D Health State Short Form (SF-6D; a subset of 6 items of the Short Form Health Survey Version 1 [33]). The SF-6D contains 6 dimensions (each with between 2 and 5 levels) and can generate 7500 different health states. Utility values were derived using Brazier's algorithm [34]. QALY health gains were estimated by calculating the area under the curve of linearly interpolated SF-6D utilities between measurements to cover the whole 6-month follow-up period. The SF-6D was used in this study because the instrument is known to be more sensitive to changes in mild to moderate physical and mental health conditions than is the EQ-5D-3L questionnaire $[35,36]$.

\section{Resource Use and Costing}

We used the Trimbos and Institute for Medical Technology Assessment "Treatment Inventory of Costs in Patients with psychiatric disorders" questionnaire (TiC-P) to collect data on health care utilization, patient and family costs, and productivity losses $[37,38]$. The TiC-P is a retrospective questionnaire with a 3-month recall period. The TiC-P was adapted for use in Germany and has been used in a large number of cost-effectiveness studies [39-41]. Costs were expressed in euros and indexed for the year 2013, the year the study was conducted, based on the German consumer price index (index factor 1.04) [42]. A reference to the National Institute for Health and Care Excellence willingness-to-pay (WTP) threshold of $£ 20,000$ $(€ 23,529)$ to $£ 30000(€ 35,294)$ per QALY gained was made where appropriate [43]. Costs were converted to pound sterling (£) using the purchasing power parities reported by the Organization for Economic Cooperation and Development. For the reference year 2013, $€ 1$ was equated to $£ 0.85$.

\section{Intervention Costs}

At the time of conducting the study, the market price of the iCBT-I provided by the GET.ON Institute was $€ 299$ (£254) per participant including all costs for developing (eg, tailoring intervention content to the target group) and delivering the intervention (eg, eCoaches providing individual feedback to participants).

\section{Health Care Costs}

We used 2 German guidelines for calculating health care costs $[44,45]$. A list of unit cost prices (ie, outpatient care) was used to compute the total health care costs on a per-participant level. Unit cost prices indexed for the year 2013 were as follows: $€ 20.92$ ( $£ 17.78$ ) for a visit to the general practitioner, $€ 68.06$ (£57.85) for an internal medicine consult, €46.55 (£39.57) for a session with a psychiatrist, and $€ 81.44$ (£69.22) for a session with a psychotherapist. Hospital stays were computed at $€ 335.52$ (£285.19) for an in-patient day in a psychiatric hospital and $€ 306.41$ (£260.45) for an in-patient day in a hospital for psychosomatic medicine and psychotherapy. Costs were estimated by multiplying the units of resource use with corresponding unit cost prices. 


\section{Medication}

The costs of prescribed medication were based on the German drug registry (Rote Liste [46]). Costs of prescribed medication are calculated as the pharmacy retail price, with the pharmacist's "clawback" (ie, wholesale margin) being accounted for. The rates of discount vary between private and statutory (public) health insurances. Therefore, we weighted the mean costs of the 3 largest packages with the same agent based on the daily defined dose by the statutory population share $(89 \%$ of the German population are statutorily insured).

\section{Patient and Family Costs}

Out-of-pocket expenses were directly obtained from participants. Costs for traveling were valued at $€ 0.30$ (£0.26) per kilometer for making trips to access health services. Time spent on the intervention and costs of informal care were valued using the opportunity cost method and were estimated at $€ 23.10$ (£19.64) per hour $[44,45]$.

\section{Costs of Productivity Losses}

Productivity losses can be caused by absenteeism (ie, days not worked) and presenteeism (ie, reduced efficiency while at work). We followed the human capital approach to value costs due to absenteeism [47]. Lost workdays due to absenteeism were valued at the corresponding gross average of participants' income per day. Lost workdays due to presenteeism were computed by taking into account the number of work days for which the participant reported reduced functioning weighted by the reported corresponding inefficiency score for those days (Osterhaus method) [48]. Productivity losses from unpaid work (ie, household work) were valued using the replacement cost method [49]. The estimated value was $€ 18.33$ ( $£ 15.58$ ) per hour (eg, the average hourly gross wage of domestic help).

\section{Analysis}

The study was not powered to statistically test differences in health-economic outcomes. Therefore, we took a probabilistic decision-making approach to make health-economic inferences [50]. We did not discount costs and effects because the analysis was limited to a 6-month time horizon.

In evaluating clinical and cost outcomes, we reported all analyses in accordance with the CONSORT statement [51]. Data were analyzed according to the intention-to-treat principle. Missing data in ISI were imputed via multiple imputation using a Markov Chain Monte Carlo multivariate imputation algorithm (SPSS 21, IBM Corp) with 10 estimations per missing value [23]. To account for missing data in the cost and utility data, we used the regression imputation procedure in Stata version 16 (StataCorp) to obtain the required predicted values [52]. Predictors of outcome and dropout were identified by (logistic) regression analyses. Identifying predictors of outcome helped us to obtain the most likely values of the outcome, whereas identifying predictors of dropout allowed us to correct for bias that might arise by differential loss to follow-up. Differences in effectiveness between study groups at 6-month follow-up were estimated using ordinary least square regression analyses. Due to baseline imbalances, QALYs were adjusted for baseline values [53]. To compare cumulative costs between study groups, a generalized linear regression model with a gamma family distribution and an identity link function was fitted and adjusted for baseline depressive symptom severity and age. The family distribution was selected based on the modified Park test [54]. The identity link function was chosen because an additive effect of the covariates was expected.

Societal costs included all cost categories, while direct medical costs used in analyses from the public health care perspective comprised intervention costs, health care costs, and medication costs. In the cost-effectiveness analysis, the incremental cost-effectiveness ratio (ICER) was calculated by dividing incremental costs (total per-participant costs or direct medical costs) by symptom-free status gained. In the cost-utility analysis, incremental costs were divided by QALYs gained. The corresponding equation was as follows: ICER $=($ CostsINT - CostsCTR) / (EffectsINT - EffectsCTR), where INT is the intervention group and CTR is the control group [47]. Although costs were gamma distributed, the difference of 2 nonnormally distributed variables (eg, incremental costs) followed a remarkably normal distribution. Hence, to handle sampling uncertainty, we bootstrapped the seemingly unrelated regression equations model ("sureg" command in Stata) to generate 2500 simulations of incremental cost and incremental effect pairs while allowing for correlated residuals of the cost and effect equations and adjusting for potential confounders (eg, baseline utilities in the effect equation; age and baseline depressive symptom severity in the cost equation) [55]. Based on the bootstrapped seemingly unrelated regression equation model, bias-corrected and accelerated 95\% CIs were obtained for incremental costs and effects. In addition, 95\% CIs around ICERs were obtained by the bootstrap acceptability method [56]. The bootstrapped cost and effect pairs were graphically represented on a cost-effectiveness plane with effects along the horizontal axis and costs along the vertical axis [47]. To assess the probability of the intervention being cost-effective at varying WTP thresholds, cost-effectiveness acceptability curves were plotted [57]. Except for the imputation of missing ISI scores, all analyses were performed using Stata version 16 (StataCorp) [52].

\section{Sensitivity Analyses}

Three sensitivity analyses were performed. Presenteeism has been previously identified as one of the main cost drivers in insomnia [20]. As there is no gold standard to measure costs due to presenteeism, we used a different approach to assess presenteeism costs in the first sensitivity analysis. Here, we calculated costs due to presenteeism based on the Health and Labor Questionnaire (HLQ) method. The Osterhaus method, used in the main analyses, tends to overestimate costs due to presenteeism because this method concentrates on the work capacity of the individual. In contrast, the HLQ method focuses on production loss that is recoverable and is not yet made up for, thus generating a lower estimate of costs [58]. In a second sensitivity analysis, we varied the costs of the intervention by plus and minus $20 \%$ and $50 \%$, respectively, to reflect uncertainties about the actual market price also including a lower price due to scaling effects. Finally, we conducted a "completers-only analysis" based on the data of the participants who completed the 6-month follow-up assessment. 


\section{Results}

\section{Study Dropout}

At posttreatment, $92.2 \%$ (118/128) of the participants completed the follow-up questionnaires, whereas at 6-month follow-up, $88.3 \%$ (113/128) did. Dropout rates did not differ between the intervention and control conditions $\left(\chi 2_{1}=1.89 ; P=.17\right)$. Study dropout was neither associated with baseline insomnia severity nor with any sociodemographic factors (lowest $P$ value $=.18$ for treatment allocation). There were no missing data due to item nonresponse.

\section{Effects}

In the intervention group, 27 out of 64 participants (42\%) reached a symptom-free status, whereas in the control group, 4 out of 64 participants $(6 \%)$ were symptom-free at 6-month follow-up [23]. Statistically significant differences favoring the intervention group were found between the intervention and control group in symptom-free status (incremental effect, $(\Delta[E]=0.30 ; 95 \%$ CI $0.16-0.43)$. On average, participants in the intervention group gained 0.36 QALYs (95\% CI 0.35-0.37) during the study period, while participants in the control condition gained 0.35 QALYs (95\% CI 0.34-0.36). Differences in adjusted incremental QALYs were statistically significant $(\Delta[\mathrm{E}]=0.02 ; 95 \%$ CI $0.01-0.03)$.

\section{Costs}

Both groups showed similar total costs within the 3-month recall period before randomization (intervention group: €2902 [£2467], 95\% CI €2111-€3693; control group: €3112 [£2645], 95\% CI $€ 2321-€ 3903)$. Table 1 presents the 6-month accumulated per-participant costs separately for different cost categories by treatment allocation. Mean direct medical costs were higher in the intervention group ( $€ 592$ [£503]; 95\% CI €444-€740) compared to the control condition ( $€ 389$ [£331]; 95\% CI $€ 242-€ 537$ ), which could largely be explained by the intervention costs that were only involved in the iCBT-I group. In contrast, both patient and family's costs, along with productivity costs, were lower in the intervention group compared to the control group, with costs related to productivity losses having the largest impact on overall societal costs. Mean per-participant total costs accrued over the 6-month follow-up period were $€ 4030$ ( $£ 3426$; 95\% CI $€ 3125-€ 4934$ ) for the intervention group and €5021 (£4268; 95\% CI €3394-€6147) for the control condition. Adjusted incremental differences in total costs were in favor of the intervention group $(\Delta[\mathrm{C}]=-€ 895$ [-£761]; $95 \%$ CI $-€ 2155$ to $€ 364$; ie, lower by $€ 895$ in the intervention group).

Table 1. Mean cumulative per-participant costs (in $€$ ) by condition over a 6-month follow-up period (based on intention-to-treat sample; N=128).

\begin{tabular}{|c|c|c|c|}
\hline Costs & $\begin{array}{l}\text { Intervention group }(\mathrm{n}=64) \text {, mean } \\
(95 \% \mathrm{CI})\end{array}$ & $\begin{array}{l}\text { Control group, }(\mathrm{n}=64) \text {, mean } \\
(95 \% \mathrm{CI})\end{array}$ & $\begin{array}{l}\text { Incremental costs, difference } \\
(95 \% \mathrm{CI})\end{array}$ \\
\hline \multicolumn{4}{|l|}{ Direct medical costs } \\
\hline Intervention costs & $299^{\mathrm{a}}$ & ${ }^{\mathrm{b}}$ & $299^{\mathrm{a}}$ \\
\hline General practitioner & $36(21$ to 51$)$ & 51 (36 to 66$)$ & -15 ( -36 to 6$)$ \\
\hline Mental health care & $150(56$ to 244$)$ & 163 (69 to 257$)$ & $-13(-146$ to 120$)$ \\
\hline Antidepressants & $2(0$ to 5$)$ & $5(2$ to 8$)$ & $-3(-7$ to 1$)$ \\
\hline Allied health services ${ }^{c}$ & 105 (34 to 176$)$ & $170(99$ to 241$)$ & $-65(-166$ to 36$)$ \\
\hline \multicolumn{4}{|l|}{ Patient and family costs } \\
\hline Informal care & 884 (226 to 1541$)$ & $1260(602$ to 1918$)$ & $-376(-1306$ to 554$)$ \\
\hline Domestic help & $310(147$ to 474$)$ & (132 to 459$)$ & $15(-217$ to 246$)$ \\
\hline Out-of-pocket expenses ${ }^{\mathrm{d}}$ & $45(7$ to 84$)$ & 73 (35 to 112$)$ & $-28(-82 \text { to } 27)^{a}$ \\
\hline Travel & $8(3$ to 13$)$ & 15 (10 to 20$)$ & $-7(-14$ to 1$)$ \\
\hline \multicolumn{4}{|l|}{ Productivity costs } \\
\hline Absenteeism & 1005 (473 to 1537$)$ & 1104 (573 to 1636$)$ & $-99(-851$ to 653$)$ \\
\hline Presenteeism & 1185 (747 to 1623$)$ & 1883 (1446 to 2321$)$ & -698 \\
\hline Total costs & $4030(2951$ to 5108$)$ & 5021 (3942 to 6099) & $-991(-2519$ to 534$)$ \\
\hline
\end{tabular}

\footnotetext{
${ }^{\mathrm{a}} \mathrm{As}$ intervention costs are fixed, no $95 \% \mathrm{CI}$ is applicable here.

${ }^{\mathrm{b}}$ Not applicable.

${ }^{\mathrm{c} I n c l u d i n g}$ physiotherapist, massage, occupational therapist, etc.

${ }^{\mathrm{d}}$ For example, allied health services without prescription.
} 


\section{Economic Evaluation}

\section{Societal Perspective}

Table 2 shows the incremental cost, effects, and cost-effectiveness ratios (based on 2500 bootstrap simulations) for the main analyses. Cost-effectiveness analysis revealed that the iCBT-I intervention resulted in more symptom-free individuals $(\Delta[\mathrm{E}]=0.30 ; 95 \% \mathrm{CI} 0.16-0.43)$ and that these health gains were achieved at lower costs $(\Delta[\mathrm{C}]=-€ 1121$ [£953]; $95 \%$ CI $-€ 3012$ to $€ 64)$. With regard to the cost-effectiveness plane, most of the replicated ICERs (94\%) fell in the south-east quadrant, indicating a $94 \%$ probability that the intervention would dominate the control condition (Figure 1). Cost-utility analysis revealed similar results compared to the cost-effectiveness analysis (Table 2). Again, most of the bootstrapped cost and effect pairs $(94 \%)$ fell in the south-east quadrant, indicating the dominance of the intervention over the control condition (Figure 2). When the societal WTP per additional QALY gained was $€ 0$, the iCBT-I intervention had a $94 \%$ probability of being more cost-effective than the control condition.

Table 2. Results of the main analyses (based on 2500 bootstrap simulations) based on societal and public health care perspectives.

\begin{tabular}{|c|c|c|c|c|c|c|c|}
\hline \multirow[t]{2}{*}{ Type of analysis } & \multirow[t]{2}{*}{$\begin{array}{l}\text { Incremental costs (in } €) \text {, } \\
\text { mean }(95 \% \mathrm{CI})^{\mathrm{a}}\end{array}$} & \multirow[t]{2}{*}{$\begin{array}{l}\text { Incremental effects, mean } \\
(95 \% \mathrm{CI})^{\mathrm{a}}\end{array}$} & \multirow[t]{2}{*}{$\begin{array}{l}\text { ICER }^{\mathrm{b}}, \text { mean }(95 \% \\
\mathrm{CI})\end{array}$} & \multicolumn{4}{|c|}{$\begin{array}{l}\text { Distribution over the cost-effectiveness } \\
\text { plane }(\%)\end{array}$} \\
\hline & & & & $\mathrm{NEQ}^{\mathrm{c}}$ & $\mathrm{NWQ}^{\mathrm{d}}$ & $\mathrm{SEQ}^{\mathrm{e}}$ & $S_{W Q}{ }^{f}$ \\
\hline \multicolumn{8}{|c|}{ Societal perspective } \\
\hline $\mathrm{CEA}^{\mathrm{g}}(\mathrm{SFS})^{\mathrm{h}}$ & $-1121(-3012$ to 64$)$ & $0.30(0.16$ to 0.43$)$ & dominant $^{\mathrm{i}}$ & 6 & - & 94 & - \\
\hline $\begin{array}{l}\text { CUA }^{\mathrm{j}}(\mathrm{SF}-6 \mathrm{D} \\
\mathrm{QALY}^{\mathrm{k}}\end{array}$ & $-1121(-3012$ to 64$)$ & $0.0183(-0.0182$ to 0.0185$)$ & dominant & 6 & - & 94 & - \\
\hline \multicolumn{8}{|c|}{ Public health care perspective } \\
\hline CEA (SFS) & 189 ( -97 to 350$)$ & $0.30(0.16$ to 0.43$)$ & $650(-215$ to 1652$)$ & 94 & - & 6 & - \\
\hline $\begin{array}{l}\text { CUA (SF-6D } \\
\text { QALY) }\end{array}$ & 189 (97 to 350$)$ & $0.0183(0.0182$ to 0.0185$)$ & $\begin{array}{l}11,285 \text { ( }-1750 \text { to } \\
27,493)\end{array}$ & 96 & - & 4 & - \\
\hline
\end{tabular}

${ }^{\mathrm{a}} 95 \%$ CIs in this column were bias-corrected and accelerated.

${ }^{b}$ ICER: incremental cost-effectiveness ratio.

${ }^{\mathrm{c}} \mathrm{NEQ}$ : north-east quadrant.

${ }^{\mathrm{d} N W Q}$ : north-west quadrant.

${ }^{\mathrm{e}} \mathrm{SEQ}$ : south-east quadrant.

${ }_{\text {SWQ: }}$ south-west quadrant.

${ }^{\mathrm{g}}$ CEA: cost-effectiveness analysis.

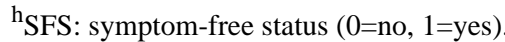

${ }^{i}$ dominant: The intervention resulted in higher effects at lower costs compared to the control condition.

${ }^{\mathrm{j}}$ CUA: cost-utility analysis.

${ }^{\mathrm{k}}$ SF-6D QALY: 6D Health State Short Form quality-adjusted life years based on the SF-12. 
Figure 1. Scatterplot of 2500 replicates of the incremental cost and effect pairs (eg, symptom-free status) from the societal perspective on the cost-effectiveness plane: internet-based cognitive behavioral therapy versus wait list control condition and cost-effectiveness acceptability curve.

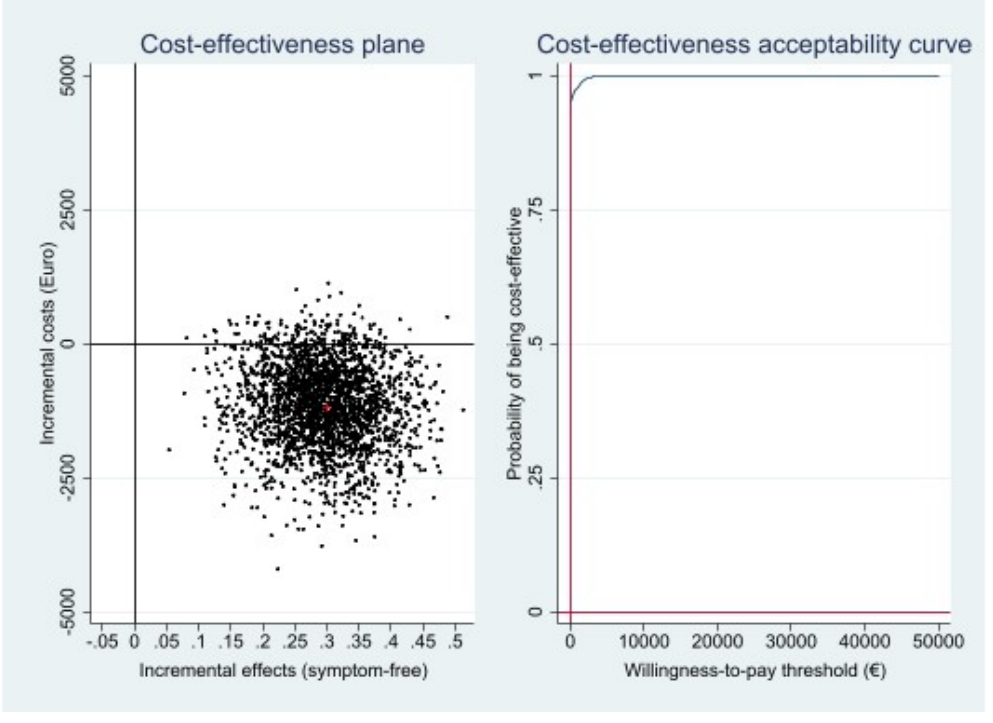

Figure 2. Scatterplot of 2500 replicates of the incremental cost and effect pairs (eg, QALYs gained) from the societal perspective on the cost-effectiveness plane: internet-based cognitive behavioral therapy for insomnia versus wait list control condition and cost-effectiveness acceptability curve. QALY: quality-adjusted life years; SF-6D: 6D Health State Short Form.

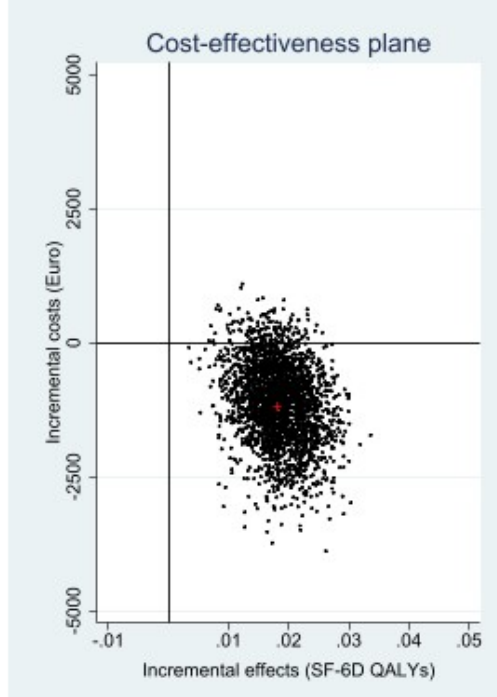

\section{Public Health Care Perspective}

From a public health care perspective, health benefits were achieved at higher costs ( $€ 189$ [£161]; 95\%CI -€97 to €350). The ICER was $€ 650$ ( $£ 553$; $95 \%$ CI $-€ 215$ to $€ 1652$ ) for 1 additional symptom-free individual. At a WTP threshold of $€ 0$, the iCBT-I intervention's probability of being cost-effective was $6 \%$. With an increase in the WTP to $€ 1500$ (£1275) per symptom-free status gained, the probability rose to $96 \%$ (Figure

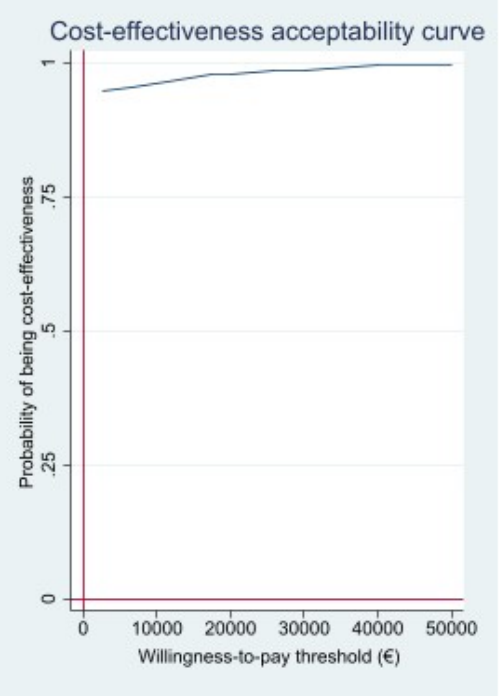

3). Cost-utility analysis revealed an ICER of $€ 11,285$ ( $£ 9592$; $95 \%$ CI $-€ 1750$ to $€ 27,493)$ per QALY gained. The corresponding cost-effectiveness acceptability curve shows a probability of $4 \%$ and $89 \%$ that the intervention would be cost-effective at WTPs of $€ 0$ and $€ 20,000(£ 17,000)$ per QALY gained, respectively. With a National Institute for Health and Care Excellence WTP threshold of $£ 20,000$ ( $€ 23,529)$ to $£ 30,000$ $(€ 35,294)$ per QALY gained [43], the probability would increase to $95 \%$ and $99 \%$, respectively (Figure 4). 
Figure 3. Scatterplot of 2500 replicates of the incremental cost and effect pairs (eg, symptom-free status) from the public health care perspective on the cost-effectiveness plane: internet-based cognitive behavioral therapy versus wait list control condition and cost-effectiveness acceptability curve.

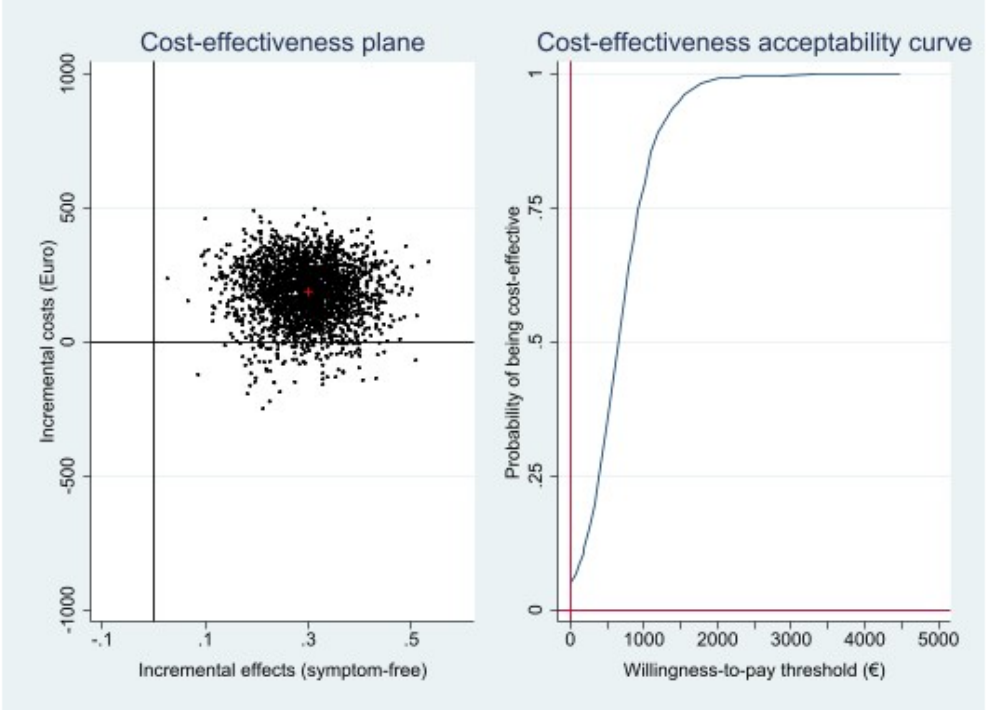

Figure 4. Scatterplot of 2500 replicates of the incremental cost and effect pairs (eg, QALYs gained) from the public health care perspective on the cost-effectiveness plane: internet-based cognitive behavioral therapy versus wait list control condition and cost-effectiveness acceptability curve. QALY: quality-adjusted life years; SF-6D: 6D Health State Short Form.

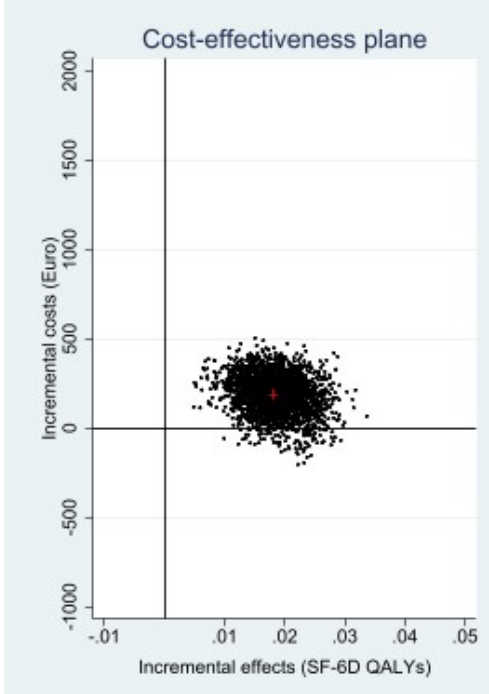

\section{Sensitivity Analyses}

Cost-effectiveness estimates based on the completer-only sample were almost identical to the main analyses, indicating that the imputation procedure did not bias the results (Table 3 ). From a societal perspective, results of the sensitivity analyses showed that neither using the HLQ method to assess costs due to presenteeism nor increasing intervention costs affected the overall conclusion that the iCBT-I intervention produces greater health gains at lower costs compared with a wait list control condition (Table 3). Using the HLQ method, the intervention's probability of being cost-effective was $72 \%$ at a WTP of $€ 0$ for both health outcomes. This probability rose to $86 \%$ at a WTP

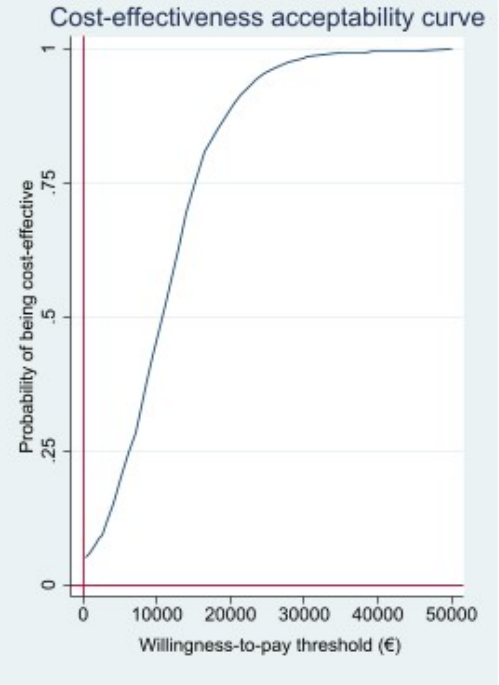

of $€ 20,000(£ 17,000)$ per QALY gained (Multimedia Appendix 1 Figure S1). Increasing or decreasing intervention costs by $20 \%$ or $50 \%$ did not affect the intervention's probability of being cost-effective compared with the main analysis (Table 3 ). From a public health care perspective, with intervention costs decreased up to $50 \%$, health effects were still gained at slightly higher costs. Increasing the intervention costs by $20 \%$ and $50 \%$ resulted in an ICER of $€ 14,380(£ 12,223)$ and $€ 19,360$ $(£ 16,456)$ per QALY gained, respectively (Table 3). At a WTP of $€ 20,000$ per QALY gained, the intervention's probability of being cost-effective was $80 \%$ and $60 \%$ (Multimedia Appendix 1 Figure S2), respectively. 
Table 3. Results of the sensitivity analyses (based on 2500 bootstrap simulations) based on the societal and public health care perspective.

\begin{tabular}{lllll}
\hline Type of analysis & $\begin{array}{l}\text { Incremental costs (in } €), \\
\text { mean }(95 \% \mathrm{CI})^{\mathrm{a}}\end{array}$ & $\begin{array}{l}\text { Incremental effects, mean }(95 \% \\
\mathrm{CI})^{\mathrm{a}}\end{array}$ & $\begin{array}{l}\text { ICER }^{\mathrm{b}} \text {, mean }(95 \% \\
\mathrm{CI})\end{array}$ & $\begin{array}{l}\text { Distribution over the cost-effectiveness } \\
\text { plane }(\%)\end{array}$ \\
& & $\mathrm{NEQ}^{\mathrm{c}} \mathrm{NWQ}^{\mathrm{d}}$ & $\mathrm{SEQ}^{\mathrm{e}} \mathrm{SWQ}^{\mathrm{f}}$ \\
\hline
\end{tabular}

Societal perspective

Presenteeism costs based on HLQ method ${ }^{\mathrm{g}}$

$\begin{array}{lllllll}\text { CEA }^{\mathrm{h}} & -459(-2155 \text { to } 796) & 0.30(0.16 \text { to } 0.43) & \text { dominant }^{\mathrm{i}} & 28 & - & 72 \\ \text { CUA }^{\mathrm{j}} & -459(-2155 \text { to } 796) & 0.0183(0.0182 \text { to } 0.0185) & \text { dominant } & 28 & - & 72\end{array}$

Intervention costs plus $20 \%$

$\begin{array}{ll}\text { CEA } & -1062(-2801 \text { to } 192) \\ \text { CUA } & -1062(-2801 \text { to } 192)\end{array}$

$0.30(0.16$ to 0.43$)$

0.0183 (0.0182 to 0.0185$)$

dominant

dominant

$0.30(0.16$ to 0.43$)$

CEA $\quad-972(-2804$ to 249$)$

0.0183 (.0182 to 0.0185$)$

dominant

dominant

$0.30(0.16$ to 0.43$)$

CEA $\quad-1181$ (-3052 to 114$)$

$0.0183(.0182$ to 0.0185$)$

dominant

dominant

$0.30(0.16$ to 0.43$)$

Intervention costs minus $\mathbf{5 0 \%}$

$\begin{array}{lll}\text { CEA } & -1271(-3068 \text { to } 18) & 0.30(0.16 \text { to } 0.43) \\ \text { CUA } & -1271(-3068 \text { to } 18) & 0.0183(.0182 \text { to } 0.0185)\end{array}$

dominant

dominant

0.32 ( 0.18 to 0.46$)$

CEA $\quad-1169(-2963$ to 625$)$

0.0188 (0.0089 to 0.028$)$

dominant

dominant

CUA $\quad-1169(-2963$ to 625$)$

Public health care perspective

Intervention costs plus $20 \%$

$\begin{array}{lll}\text { CEA } & 246(-59 \text { to } 405) & 0.30(0.16 \text { to } 0.43) \\ \text { CUA } & 246(-59 \text { to } 405) & 0.0183(0.0182 \text { to } 0.0185)\end{array}$

$831(59-1778) \quad 98$

14,380 (1135 to 98 $31,826)$

\section{Intervention costs plus 50\%}

$\begin{array}{ll}\text { CEA } & 336(38 \text { to } 503) \\ \text { CUA } & 336(38 \text { to } 503)\end{array}$

$0.30(0.16$ to 0.43$)$

1129 (306 to 2137) 100

0.0183 (0.0182 to 0.0185$)$

19,360 (4671 to 100 $40,673)$

\section{Intervention costs minus $20 \%$}

$\begin{array}{ll}\text { CEA } & 127(-157 \text { to } 295) \\ \text { CUA } & 127(-157 \text { to } 295)\end{array}$

Intervention costs minus $\mathbf{5 0 \%}$

$\begin{array}{ll}\text { CEA } & 37(-258 \text { to } 201) \\ \text { CUA } & 37(-258 \text { to } 201)\end{array}$

\section{Completer analysis}

$\begin{array}{ll}\text { CEA } & 206 \text { ( }-145 \text { to } 395) \\ \text { CUA } & 206 \text { ( }-145 \text { to } 395)\end{array}$

$0.30(0.16$ to 0.43$)$
$0.0183(0.0182$ to 0.0185$)$

$0.30(0.16$ to 0.43$)$

0.0183 (0.0182 to 0.0185 )

0.32 ( 0.18 to 0.46$)$

0.0188 (0.0089 to 0.028$)$

$\begin{array}{lll}413(-400 \text { to } 1185) & 87 & - \\ 7826(-4120 \text { to } & 90 & - \\ 22,565) & & \end{array}$

13

10

$\begin{array}{lllll}129(-636 \text { to } 838) & 66 & - & 34 & - \\ 2384(-9114 \text { to } & 66 & - & 34 & - \\ 15,017) & & & & \end{array}$

${ }^{\mathrm{a}} 95 \%$ CIs in this column were bias-corrected and accelerated. 
bICER: incremental cost-effectiveness ratio.

${ }^{\mathrm{c}} \mathrm{NEQ}$ : north-east quadrant.

${ }^{\mathrm{d}} \mathrm{NWQ}$ : north-west quadrant.

e SEQ: south-east quadrant.

${ }^{\mathrm{f}} \mathrm{SWQ}$ : south-west quadrant.

${ }^{\mathrm{g}}$ Costs due to presenteeism based on the Health and Labour Questionnaire method.

${ }^{\mathrm{h}} \mathrm{CEA}$ : cost-effectiveness analysis.

idominant: The intervention resulted in higher effects at lower costs compared to the control.

${ }^{\mathrm{j}} \mathrm{CUA}$ : cost-utility analysis: quality-adjusted life years.

\section{Discussion}

\section{Principal Results}

Our study was set out to evaluate the cost-effectiveness and cost-utility of a guided iCBT-I intervention as an adjunct to usual care to reduce insomnia symptoms in schoolteachers in comparison with a wait list control condition with unrestricted access to TAU from a societal and a public health care perspective. Statistically significant differences favoring the intervention group were found for both health outcomes (symptom-free status and QALYs). From a societal perspective, the iCBT-I intervention dominated the wait list-control condition, meaning that the iCBT-I intervention has better health effects for less costs than does usual care in schoolteachers with insomnia. From a public health care perspective, the ICERs were $€ 650$ and $€ 11,285$ for a symptom-free individual and QALY gained, respectively. At a WTP threshold of $€ 20,000$ per QALY gained, the intervention's probability of being cost-effective was $89 \%$.

\section{Comparison With Prior Work}

Although the effectiveness of iCBT-I is well established [15], there is a critical gap in health-economic evidence for iCBT-I To our knowledge, this is the first trial-based economic evaluation of an iCBT-I intervention to reduce insomnia symptoms using a societal and public health care perspective. As such, results from our trial add to the converging evidence pointing to the cost-effectiveness of CBT interventions for insomnia. Thiart et al [20] used the same study to evaluate the cost and benefits of the iCBT-I intervention as seen from an employer's perspective. Results of the current health-economic evaluation line up agreeably with these findings. Baka et al [21] compared a guided iCBT-I intervention to care as usual for insomnia patients in general practice. Analogous to our findings, mean societal costs were lower in the intervention group than in the care as usual group, and, in contrast to our results, the cost-utility analyses revealed a lower probability (69\%) of the intervention being cost-effective compared to care as usual at a ceiling ratio of $€ 30,000$ per QALY gained. This difference could be due to different types of control conditions used (care as usual vs wait list control). Applying an employer's or societal perspective seems to generate incremental costs favoring interventions groups when participants are employees, or at least in the productive age groups. In addition, our findings match with available health-economic evidence from a recent systematic review $(\mathrm{N}=7)$ showing that $\mathrm{CBT}-\mathrm{I}$ was cost-effective compared to pharmacotherapy or no treatment [19].
Our findings from the public health care perspective showing that the iCBT intervention resulted in better health effects but achieved this at higher costs are also in line with findings from this systematic review [19]. Three trial-based economic evaluations employing a public health care perspective showed that CBT-I led to greater health improvements at higher costs compared to either TAU $[59,60]$ or a wait list control condition [61], with time horizons ranging from 8 weeks to 6 months. In terms of QALYs gained, studies reported a low (34\%) [61] and high (99\%) [59] probability of CBT-I being cost-effective at a maximum WTP of $£ 30,000$ ( $€ 31,727)$ in the United Kingdom. Watanabe et al [60] reported a $90 \%$ chance of CBT-I being cost-effective at a WTP threshold of US\$40,000 $(€ 29,400)$ per QALY gained. In contrast, one study conducted from a public health care perspective showed that CBT-I was cheaper and more effective than TAU. However, there was large uncertainty around cost estimates resulting in a moderate probability (70\%) of being cost-effective at a WTP of $£ 30,000$ ( $€ 31,727)$ [62].

\section{Limitations}

This study has some limitations. First, the time horizon of this study was limited to 6 months. However, results of an economic model investigating the long-term cost-effectiveness of CBT-I among long-term hypnotic drug users with chronic sleep difficulties compared to TAU indicated that any increase in the timeframe of the economic evaluation produces substantial reductions in the incremental costs per QALY gained. The cost-effectiveness of CBT-I improved even when treatment effects were reduced radically over time [59]. Further studies should thus assess the long-term clinical and cost-effectiveness of iCBT-I to reaffirm its long-term cost-effectiveness. Second, the iCBT-I intervention was compared to a wait list control condition in the present trial. Although patients in the control group had full access to treatment as usual, we cannot rule out a potential nocebo effect in the wait list control condition [63]. In addition, pharmacoeconomic guidelines recommend standard care (eg, face-to-face CBT-I) as comparator [64]. Future studies should thus directly compare the cost-effectiveness of iCBT-I versus face-to-face CBT-I. Third, although the sample size in this trial was sufficient to demonstrate clinical effectiveness, it needs emphasizing that much larger sample sizes are required for hypothesis testing in economic studies due to the skewness of costs relative to normally distributed health effects [65]. Therefore, it is recommended that future studies employ larger sample sizes to allow for better evaluation of cost changes and sustainability of interventions like iCBT-I. Fourth, we only used the SF-6D to compute utilities and QALYs. However, the choice for the SF-6D (rather than its alternative the EQ-5D-3L [66]) matters, even to the point where decision-makers have to regard 
a new intervention as cost-effective or not [67]. In the current study, we flanked the cost-utility analysis (with QALYs) by a cost-effectiveness analysis (with improvements in insomnia) and both economic evaluations led to the same conclusion of the iCBT-I intervention being the preferred option. Nevertheless, future studies should employ different instruments to compute QALYs. Fifth, our results may only be generalized to professions with similar characteristics, such as flexible working hours, loose boundaries between work and private life, and work-home interference. Sixth, the trial has been conducted in a highly educated sample. Hence, we cannot predict the uptake of such an intervention in participants with a lower education level or among those with lower-income status. A recent individual participant data meta-analysis revealed, however, that education was not associated with differential treatment effects of an iCBT intervention to prevent depression [68] although other evidence suggests that better treatment adherence is predicted by higher education [69]. Attrition has been suggested to be an issue, especially in internet-delivered interventions [70]. It is thus warranted to conduct research into the willingness of specific population segments to fully engage in such interventions (ie, how uptake and adherence rates of iCBT interventions could be increased among individuals with less education). Finally, the research context might have led to a self-selection of individuals who might have been more motivated and committed to engage in the iCBT-I intervention than is assumed outside a research context. As a result, findings might not be generalizable to the wider population, but might be representative of specifically those willing to use internet-based interventions in the first place.

\section{Clinical Implications and Future Research}

American and European guidelines recommend CBT as the first-line treatment for insomnia disorder [10,11]. Our study supports this recommendation by showing that a guided iCBT-I intervention may reduce insomnia symptoms and improve health-related quality of life. iCBT interventions for mental disorders have often been introduced as potential cost-saving alternatives to face-to-face individual or group therapy $[71,72]$. Findings from our study add to the evidence base that delivering cognitive-behavioral therapy over the internet has a high probability of being cost-effective in reducing insomnia symptoms among employees. In view of scarce resources and rising costs in health care systems, evidence-based guidance regarding cost-effectiveness of iCBT-I can potentially help to inform decision-makers to the choice of first-line treatments of insomnia. However, future studies should directly compare iCBT-I with face-to-face-delivered CBT-I.

Considering the shortage of therapists and available resources [13], a rather low uptake of professional help [3], and the potential to scale up iCBT-I interventions to efficiently alleviate the health and economic burden caused by insomnia, it would be worthwhile to integrate this type of intervention into routine practice. However, some risks need to be taken into account when scaling up this intervention. Involving individual eCoaches may hamper scaling up the intervention. The support offered by an eCoach may not only affect clinical effectiveness and cost-effectiveness of the intervention but also the target group's willingness to participate in this intervention, thereby influencing intervention effects at the population level. Thus, future studies should compare the acceptability, effectiveness, and cost-effectiveness of guided and unguided iCBT-I interventions. In addition, there are no guarantees that adherence and (by proxy) effectiveness will be maintained if this sort of unsupported iCBT-I intervention is scaled up in the population. Finally, the same technical resources available in the research setting (eg, stable and secure internet connections) may not be available when the intervention is scaled up.

\section{Conclusions}

Findings from our trial indicate that iCBT could be considered as good value for money in insomnia therapy. Given the evidence for the effectiveness of iCBT-I interventions to reduce insomnia symptoms, the potential scalability and cost-effectiveness of these interventions might strategically pave the way to alleviate the health and economic burden related to insomnia disorder (and its sequelae) in an affordable way. However, before a nationwide dissemination can be considered, future studies need to evaluate the comparative clinical and economic outcomes of guided and unguided iCBT-I interventions, and to determine what works best for whom such that the deployment of the intervention can optimally target the right population segments. Moreover, implementation studies are needed to clarify the real-world effects of these interventions and to gain insights into the willingness of specific population segments to fully engage in them (eg, individuals with a low education level or those of low-income status).

\section{Acknowledgments}

DDE, DL, and MB obtained the funding for this study. DDE, DL, HR, MB, and HH contributed to the design of the clinical study. HH and DDE analyzed the clinical data. CB designed and performed the health-economic evaluation with support from FS. CB had full access to the clinical and economic data and takes full responsibility for the integrity of the data and the accuracy of the health-economic data analyses. CB drafted the manuscript; FS, KS, DL, and DDE supervised the writing process. All authors contributed to the further writing of the manuscript and approved the final manuscript.

This was not an industry-supported study. The European Union funded this study (European Regional Development Fund: ZW6-80119999 and CCI 2007DE161PR001). The funder did not have a role in study design; data collection, analysis, and interpretation of results; or the decision to publish the study results. 


\section{Conflicts of Interest}

DDE, DL, and MB are stakeholders of the GET.ON Institute, which aims to implement scientific findings related to digital health interventions into routine care. HH serves as business developer at the GET.ON Institute. DDE has served as a consultant on the scientific advisory boards of Sanofi, Novartis, Minddistrict, Lantern, Schoen Kliniken, Ideamed, as well as German health insurance companies (BARMER and Techniker Krankenkasse) and a number of federal chambers for psychotherapy. The other authors have no conflicts of interest to declare.

\section{Multimedia Appendix 1}

Additional figures.

[PDF File (Adobe PDF File), 432 KB-Multimedia Appendix 1]

\section{Multimedia Appendix 2}

CONSORT-EHEALTH Checklist (V.1.6.1).

[PDF File (Adobe PDF File), 11399 KB-Multimedia Appendix 2]

\section{References}

1. American Psychiatric Association. Diagnostic and Statistical Manual of Mental Disorders. 5th ed. Washington, DC: American Psychiatric Association; 2013.

2. Ohayon MM. Epidemiology of insomnia: what we know and what we still need to learn. Sleep Med Rev 2002 Apr;6(2):97-111. [doi: 10.1053/smrv.2002.0186] [Medline: 12531146]

3. Morin CM, LeBlanc M, Bélanger L, Ivers H, Mérette C, Savard J. Prevalence of insomnia and its treatment in Canada. Can J Psychiatry 2011 Sep;56(9):540-548. [doi: 10.1177/070674371105600905] [Medline: 21959029]

4. Wardle-Pinkston S, Slavish DC, Taylor DJ. Insomnia and cognitive performance: A systematic review and meta-analysis. Sleep Med Rev 2019 Dec;48:101205. [doi: 10.1016/j.smrv.2019.07.008] [Medline: 31522135]

5. Kyle SD, Morgan K, Espie CA. Insomnia and health-related quality of life. Sleep Med Rev 2010 Feb;14(1):69-82. [doi: 10.1016/j.smrv.2009.07.004] [Medline: 19962922]

6. Hertenstein E, Feige B, Gmeiner T, Kienzler C, Spiegelhalder K, Johann A, et al. Insomnia as a predictor of mental disorders: a systematic review and meta-analysis. Sleep Med Rev 2019 Feb;43:96-105. [doi: 10.1016/j.smrv.2018.10.006] [Medline: 30537570]

7. Espie CA, Pawlecki B, Waterfield D, Fitton K, Radocchia M, Luik AI. Insomnia symptoms and their association with workplace productivity: cross-sectional and pre-post intervention analyses from a large multinational manufacturing company. Sleep Health 2018 Jun;4(3):307-312. [doi: 10.1016/j.sleh.2018.03.003] [Medline: 29776626]

8. Hillman D, Mitchell S, Streatfeild J, Burns C, Bruck D, Pezzullo L. The economic cost of inadequate sleep. Sleep 2018 Aug 01;41(8):1-13. [doi: 10.1093/sleep/zsy083] [Medline: 29868785]

9. Léger D, Bayon V. Societal costs of insomnia. Sleep Med Rev 2010 Dec;14(6):379-389. [doi: 10.1016/j.smrv.2010.01.003] [Medline: 20359916]

10. Qaseem A, Kansagara D, Forciea MA, Cooke M, Denberg TD, Clinical Guidelines Committee of the American College of Physicians. Management of chronic insomnia disorder in adults: a clinical practice guideline from the American College of Physicians. Ann Intern Med 2016 Jul 19;165(2):125-133. [doi: 10.7326/M15-2175] [Medline: 27136449]

11. Riemann D, Baglioni C, Bassetti C, Bjorvatn B, Dolenc Groselj L, Ellis JG, et al. European guideline for the diagnosis and treatment of insomnia. J Sleep Res 2017 Dec;26(6):675-700 [FREE Full text] [doi: 10.1111/jsr.12594] [Medline: 28875581]

12. van Straten A, van der Zweerde T, Kleiboer A, Cuijpers P, Morin CM, Lancee J. Cognitive and behavioral therapies in the treatment of insomnia: a meta-analysis. Sleep Med Rev 2018 Apr;38:3-16. [doi: 10.1016/j.smrv.2017.02.001] [Medline: 28392168]

13. Luik AI, van der Zweerde T, van Straten A, Lancee J. Digital delivery of cognitive behavioral therapy for insomnia. Curr Psychiatry Rep 2019 Jun 04;21(7):50 [FREE Full text] [doi: 10.1007/s11920-019-1041-0] [Medline: $\underline{31161406]}$

14. Espie CA. "Stepped care": a health technology solution for delivering cognitive behavioral therapy as a first line insomnia treatment. Sleep 2009 Dec;32(12):1549-1558 [FREE Full text] [doi: 10.1093/sleep/32.12.1549] [Medline: 20041590]

15. Zachariae R, Lyby MS, Ritterband LM, O'Toole MS. Efficacy of internet-delivered cognitive-behavioral therapy for insomnia - A systematic review and meta-analysis of randomized controlled trials. Sleep Med Rev 2016 Dec;30:1-10. [doi: 10.1016/j.smrv.2015.10.004] [Medline: 26615572]

16. Mohit B, Cohen JT. Trends of cost-effectiveness studies in sleep medicine. Sleep Med 2019 Jan;53:176-180. [doi: 10.1016/j.sleep.2018.06.001] [Medline: $\underline{\text { 30282589] }}$

17. Botteman M. Health economics of insomnia therapy: implications for policy. Sleep Med 2009 Sep;10 Suppl 1:S22-S25. [doi: 10.1016/j.sleep.2009.07.001] [Medline: 19647482]

18. Wickwire EM, Shaya FT, Scharf SM. Health economics of insomnia treatments: The return on investment for a good night's sleep. Sleep Med Rev 2016 Dec;30:72-82. [doi: 10.1016/j.smrv.2015.11.004] [Medline: 26874067] 
19. Natsky AN, Vakulin A, Chai-Coetzer CL, Lack L, McEvoy RD, Lovato N, et al. Economic evaluation of cognitive behavioural therapy for insomnia (CBT-I) for improving health outcomes in adult populations: a systematic review. Sleep Med Rev 2020 Jul 09;54:101351. [doi: 10.1016/j.smrv.2020.101351] [Medline: 32739824]

20. Thiart H, Ebert DD, Lehr D, Nobis S, Buntrock C, Berking M, et al. Internet-based cognitive behavioral therapy for insomnia: a health economic evaluation. Sleep 2016 Oct 01;39(10):1769-1778 [FREE Full text] [doi: 10.5665/sleep.6152] [Medline: $\underline{27450686}$ ]

21. Baka A, Van der Zweerde T, Lancee J, Bosmans J, Van Straten A. PMH31 cost-effectiveness of guided internet-delivered cognitive behavioral therapy in comparison with care-as-usual for patients with insomnia in general practice. Value in Health 2019 Nov;22:S686. [doi: 10.1016/j.jval.2019.09.1505]

22. Thiart H, Lehr D, Ebert DD, Sieland B, Berking M, Riper H. Log in and breathe out: efficacy and cost-effectiveness of an online sleep training for teachers affected by work-related strain--study protocol for a randomized controlled trial. Trials 2013 Jun 11;14:169 [FREE Full text] [doi: 10.1186/1745-6215-14-169] [Medline: 23759035]

23. Thiart H, Lehr D, Ebert DD, Berking M, Riper H. Log in and breathe out: internet-based recovery training for sleepless employees with work-related strain - results of a randomized controlled trial. Scand J Work Environ Health 2015 Mar;41(2):164-174. [doi: 10.5271/sjweh.3478] [Medline: 25590336]

24. Husereau D, Drummond M, Petrou S, Carswell C, Moher D, Greenberg D, et al. Consolidated Health Economic Evaluation Reporting Standards (CHEERS)--explanation and elaboration: a report of the ISPOR Health Economic Evaluation Publication Guidelines Good Reporting Practices Task Force. Value Health 2013;16(2):231-250 [FREE Full text] [doi: 10.1016/j.jval.2013.02.002] [Medline: 23538175]

25. Ramsey SD, Willke RJ, Glick H, Reed SD, Augustovski F, Jonsson B, et al. Cost-effectiveness analysis alongside clinical trials II-An ISPOR Good Research Practices Task Force report. Value Health 2015 Mar;18(2):161-172 [FREE Full text] [doi: 10.1016/j.jval.2015.02.001] [Medline: 25773551]

26. Siebern AT, Manber R. Insomnia and its effective non-pharmacologic treatment. Med Clin North Am 2010 May;94(3):581-591. [doi: 10.1016/j.mcna.2010.02.005] [Medline: 20451034]

27. Cuijpers P, van Straten A, Warmerdam L. Behavioral activation treatments of depression: a meta-analysis. Clin Psychol Rev 2007 Apr;27(3):318-326. [doi: 10.1016/j.cpr.2006.11.001] [Medline: 17184887]

28. Wells A. Metacognitive Therapy for Anxiety and Depression. New York: The Guilford Press; 2009.

29. Emmons RA, McCullough ME. Counting blessings versus burdens: an experimental investigation of gratitude and subjective well-being in daily life. J Pers Soc Psychol 2003 Feb;84(2):377-389. [doi: 10.1037//0022-3514.84.2.377] [Medline: 12585811]

30. Kreiner GE, Hollensbe EC, Sheep ML. Balancing borders and bridges: negotiating the work-home interface via boundary work tactics. AMJ 2009 Aug;52(4):704-730. [doi: 10.5465/amj.2009.43669916]

31. Morin CM, Belleville G, Bélanger L, Ivers H. The Insomnia Severity Index: psychometric indicators to detect insomnia cases and evaluate treatment response. Sleep 2011 May 01;34(5):601-608 [FREE Full text] [doi: 10.1093/sleep/34.5.601] [Medline: 21532953]

32. Thorndike FP, Ritterband LM, Saylor DK, Magee JC, Gonder-Frederick LA, Morin CM. Validation of the insomnia severity index as a web-based measure. Behav Sleep Med 2011;9(4):216-223. [doi: 10.1080/15402002.2011.606766] [Medline: 22003975]

33. Brazier JE, Roberts J. The estimation of a preference-based measure of health from the SF-12. Med Care 2004 Sep;42(9):851-859. [doi: 10.1097/01.mlr.0000135827.18610.0d] [Medline: 15319610]

34. Brazier J, Rowen D, Hanmer J. Revised SF-6D scoring programmes: a summary of improvements. PRO newsletter 2008;40:14-15. [doi: 10.4135/9781412971980.n298]

35. Brazier J, Roberts J, Tsuchiya A, Busschbach J. A comparison of the EQ-5D and SF-6D across seven patient groups. Health Econ 2004 Sep;13(9):873-884. [doi: 10.1002/hec.866] [Medline: 15362179]

36. Brazier J, Connell J, Papaioannou D, Mukuria C, Mulhern B, Peasgood T, et al. A systematic review, psychometric analysis and qualitative assessment of generic preference-based measures of health in mental health populations and the estimation of mapping functions from widely used specific measures. Health Technol Assess 2014 May; 18(34):vii-viii, xiii [FREE Full text] [doi: 10.3310/hta18340] [Medline: 24857402]

37. Bouwmans C, De JK, Timman R, Zijlstra-Vlasveld M, Van der Feltz-Cornelis C, Tan SS, et al. Feasibility, reliability and validity of a questionnaire on healthcare consumption and productivity loss in patients with a psychiatric disorder (TiC-P). BMC Health Serv Res 2013;13:217 [FREE Full text] [doi: 10.1186/1472-6963-13-217] [Medline: 23768141]

38. Hakkaart-van RLV, Donker M, Tiemens B. Manual Trimbos/iMTA questionnaire for Costs associated with Psychiatric illness (TiC-P). Rotterdam: Erasmus University; 2002.

39. Buntrock C, Berking M, Smit F, Lehr D, Nobis S, Riper H, et al. Preventing depression in adults with subthreshold depression: health-economic evaluation alongside a pragmatic randomized controlled trial of a web-based intervention. J Med Internet Res 2017 Jan 04;19(1):e5 [FREE Full text] [doi: 10.2196/jmir.6587] [Medline: 28052841]

40. Kählke F, Buntrock C, Smit F, Berking M, Lehr D, Heber E, et al. Economic evaluation of an internet-based stress management intervention alongside a randomized controlled trial. JMIR Ment Health 2019 May 15;6(5):e10866 [FREE Full text] [doi: 10.2196/10866] [Medline: $\underline{31094355]}$ 
41. Nobis S, Ebert DD, Lehr D, Smit F, Buntrock C, Berking M, et al. Web-based intervention for depressive symptoms in adults with types 1 and 2 diabetes mellitus: a health economic evaluation. Br J Psychiatry 2018 Dec;212(4):199-206. [doi: 10.1192/bjp.2018.10] [Medline: 30071909]

42. Exchange rates (indicator). OECD Data. 2015. URL: https://data.oecd.org/conversion/exchange-rates.htm [accessed 2016-08-30]

43. McCabe C, Claxton K, Culyer AJ. The NICE cost-effectiveness threshold: what it is and what that means. Pharmacoeconomics 2008;26(9):733-744. [doi: 10.2165/00019053-200826090-00004] [Medline: 18767894]

44. Krauth C, Hessel F, Hansmeier T, Wasem J, Seitz R, Schweikert B. [Empirical standard costs for health economic evaluation in Germany -- a proposal by the working group methods in health economic evaluation]. Gesundheitswesen 2005 Oct;67(10):736-746. [doi: 10.1055/s-2005-858698] [Medline: 16235143]

45. Bock J, Brettschneider C, Seidl H, Bowles D, Holle R, Greiner W, et al. [Calculation of standardised unit costs from a societal perspective for health economic evaluation]. Gesundheitswesen 2015 Jan;77(1):53-61. [doi: 10.1055/s-0034-1374621] [Medline: 25025287]

46. Rote Liste 2013. Frankfurt/Main: Rote Liste Service GmbH; 2013:3939192708.

47. Drummond M, Sculpher M, Torrance G, O'Brian B, Stoddart G. Methods for the Economic Evaluation of Health Care Programmes. 3rd ed. Oxford: Oxford University Press; 2005.

48. Osterhaus JT, Gutterman DL, Plachetka JR. Healthcare resource and lost labour costs of migraine headache in the US. Pharmacoeconomics 1992 Jul;2(1):67-76. [doi: 10.2165/00019053-199202010-00008] [Medline: 10146980]

49. Krol M, Brouwer W. Unpaid work in health economic evaluations. Soc Sci Med 2015 Nov;144:127-137. [doi: 10.1016/j.socscimed.2015.09.008] [Medline: 26421997]

50. Briggs AH, Gray AM. Handling uncertainty in economic evaluations of healthcare interventions. BMJ 1999 Sep 04;319(7210):635-638 [FREE Full text] [doi: 10.1136/bmj.319.7210.635] [Medline: 10473486]

51. Eysenbach G, CONSORT-EHEALTH Group. CONSORT-EHEALTH: improving and standardizing evaluation reports of Web-based and mobile health interventions. J Med Internet Res 2011;13(4):e126 [FREE Full text] [doi: 10.2196/jmir.1923] [Medline: 22209829]

52. StataCorp. Stata Statistical Software: Release 13. College Station. Texas: StataCorp LP; 2013.

53. Manca A, Hawkins N, Sculpher MJ. Estimating mean QALYs in trial-based cost-effectiveness analysis: the importance of controlling for baseline utility. Health Econ 2005 May;14(5):487-496. [doi: 10.1002/hec.944] [Medline: 15497198]

54. Manning WG, Mullahy J. Estimating log models: to transform or not to transform? Journal of Health Economics 2001 Jul;20(4):461-494. [doi: 10.1016/s0167-6296(01)00086-8]

55. Willan AR, Lin DY, Manca A. Regression methods for cost-effectiveness analysis with censored data. Stat Med 2005 Jan 15;24(1):131-145. [doi: 10.1002/sim.1794] [Medline: 15515137]

56. Glick H, Doshi J, Sonnad S, Polsky D. Economic Evaluation in Clinical Trials. Oxford: Oxford University Press; 2014.

57. Fenwick E, O'Brien BJ, Briggs A. Cost-effectiveness acceptability curves--facts, fallacies and frequently asked questions. Health Econ 2004 May;13(5):405-415. [doi: 10.1002/hec.903] [Medline: 15127421]

58. Drummond M, McGuire A. Economic Evaluation in Health Care: Merging Theory with Practice. Oxford: Oxford University Press; 2001.

59. Morgan K, Dixon S, Mathers N, Thompson J, Tomeny M. Psychological treatment for insomnia in the regulation of long-term hypnotic drug use. Health Technol Assess 2004 Feb;8(8):iii-iv, 1 [FREE Full text] [doi: 10.3310/hta8080] [Medline: 14960254]

60. Watanabe N, Furukawa TA, Shimodera S, Katsuki F, Fujita H, Sasaki M, et al. Cost-effectiveness of cognitive behavioral therapy for insomnia comorbid with depression: analysis of a randomized controlled trial. Psychiatry Clin Neurosci 2015 Jun;69(6):335-343 [FREE Full text] [doi: 10.1111/pcn.12237] [Medline: 25205008]

61. Bonin E, Beecham J, Swift N, Raikundalia S, Brown JS. Psycho-educational CBT-Insomnia workshops in the community. A cost-effectiveness analysis alongside a randomised controlled trial. Behav Res Ther 2014 Apr;55:40-47. [doi: 10.1016/j.brat.2014.01.005] [Medline: 24607500]

62. Tsiachristas A, Waite F, Freeman D, Luengo-Fernandez R. Cost-effectiveness of cognitive-behavioural therapy for sleep disorder added to usual care in patients with schizophrenia: the BEST study. BJPsych Open 2018 May;4(3):126-135 [FREE Full text] [doi: 10.1192/bjo.2018.2] [Medline: 29971156]

63. Furukawa TA, Noma H, Caldwell DM, Honyashiki M, Shinohara K, Imai H, et al. Waiting list may be a nocebo condition in psychotherapy trials: a contribution from network meta-analysis. Acta Psychiatr Scand 2014 Sep;130(3):181-192. [doi: 10.1111/acps.12275] [Medline: 24697518]

64. Sacristán JA, Abellán-Perpiñán JM, Dilla T, Soto J, Oliva J. Some reflections on the use of inappropriate comparators in CEA. Cost Eff Resour Alloc 2020 Aug 27;18(1):29 [FREE Full text] [doi: 10.1186/s12962-020-00226-8] [Medline: 32874138]

65. Briggs A. Economic evaluation and clinical trials: size matters. BMJ 2000 Dec 02;321(7273):1362-1363 [FREE Full text] [doi: 10.1136/bmj.321.7273.1362] [Medline: 11099268]

66. Brooks R. EuroQol: the current state of play. Health Policy 1996 Jul;37(1):53-72. [doi: 10.1016/0168-8510(96)00822-6] [Medline: 10158943] 
67. Davis JC, Liu-Ambrose T, Khan KM, Robertson MC, Marra CA. SF-6D and EQ-5D result in widely divergent incremental cost-effectiveness ratios in a clinical trial of older women: implications for health policy decisions. Osteoporos Int 2012 Jul;23(7):1849-1857 [FREE Full text] [doi: 10.1007/s00198-011-1770-3] [Medline: 21909728]

68. Reins JA, Buntrock C, Zimmermann J, Grund S, Harrer M, Lehr D, et al. Efficacy and moderators of internet-based interventions in adults with subthreshold depression: an individual participant data meta-analysis of randomized controlled trials. Psychother Psychosom 2020 Jun 16:1-13 [FREE Full text] [doi: 10.1159/000507819] [Medline: 32544912]

69. Batterham PJ, Neil AL, Bennett K, Griffiths KM, Christensen H. Predictors of adherence among community users of a cognitive behavior therapy website. Patient Prefer Adherence 2008 Feb 02;2:97-105 [FREE Full text] [Medline: 19920949]

70. Price M, Gros DF, McCauley JL, Gros KS, Ruggiero KJ. Nonuse and dropout attrition for a web-based mental health intervention delivered in a post-disaster context. Psychiatry 2012;75(3):267-284 [FREE Full text] [doi: 10.1521/psyc.2012.75.3.267] [Medline: 22913502]

71. Donker T, Blankers M, Hedman E, Ljótsson B, Petrie K, Christensen H. Economic evaluations of Internet interventions for mental health: a systematic review. Psychol Med 2015 Dec;45(16):3357-3376. [doi: 10.1017/S0033291715001427] [Medline: 26235445]

72. Paganini S, Teigelkötter W, Buntrock C, Baumeister H. Economic evaluations of internet- and mobile-based interventions for the treatment and prevention of depression: a systematic review. J Affect Disord 2018 Jan 01;225:733-755. [doi: 10.1016/j.jad.2017.07.018] [Medline: 28922737]

\author{
Abbreviations \\ (i)CBT-I: (internet-based) cognitive behavioral therapy for insomnia \\ CHEERS: Consolidated Health Economic Evaluation Reporting Standards \\ CONSORT: Consolidated Standards of Reporting Trials \\ HLQ: Health and Labor Questionnaire \\ ICER: incremental cost effect ratio \\ ISI: Insomnia Severity Index \\ ISPOR: International Society for Pharmacoeconomics and Outcomes Research \\ QALY: quality-adjusted life years \\ SF-6D: 6D Health State Short Form \\ SFS: symptom-free status \\ TAU: treatment-as-usual \\ TiC-P: Treatment Inventory of Costs in Patients with psychiatric disorders \\ WTP: willingness to pay
}

Edited by G Eysenbach; submitted 09.11.20; peer-reviewed by J Li; comments to author 30.11.20; revised version received 12.12.20;
accepted 17.04.21; published 24.05.21
Please cite as:
Buntrock C, Lehr D, Smit F, Horvath H, Berking M, Spiegelhalder K, Riper H, Ebert DD
Guided Internet-Based Cognitive Behavioral Therapy for Insomnia: Health-Economic Evaluation From the Societal and Public Health
Care Perspective Alongside a Randomized Controlled Trial
J Med Internet Res 2021;23(5):e25609
URL: $\underline{\text { https://www.jmir.org/2021/5/e25609 }}$
doi: $\underline{10.2196 / 25609}$
PMID:

(C) Claudia Buntrock, Dirk Lehr, Filip Smit, Hanne Horvath, Matthias Berking, Kai Spiegelhalder, Heleen Riper, David Daniel Ebert. Originally published in the Journal of Medical Internet Research (https://www.jmir.org), 24.05.2021. This is an open-access article distributed under the terms of the Creative Commons Attribution License (https://creativecommons.org/licenses/by/4.0/), which permits unrestricted use, distribution, and reproduction in any medium, provided the original work, first published in the Journal of Medical Internet Research, is properly cited. The complete bibliographic information, a link to the original publication on https://www.jmir.org/, as well as this copyright and license information must be included. 